\title{
Materials for Micro- and Nanofluidics
}

\section{Paul J.A. Kenis and Abraham D. Stroock, Guest Editors}

\begin{abstract}
Over the last two decades, our ability to create networks of fluidic channels of submillimeter or even sub-micrometer diameters has led to a wide range of microchemical applications. Whereas early efforts were directed toward the development of microanalysis systems, in more recent times the development of microreactors and tools for biotechnology and basic biological studies has emerged. This issue of MRS Bulletin highlights the many different ways in which material properties are crucial in the fabrication, assembly, and operation of micro- and nanofluidic systems. Choice-of-material considerations range from an assessment of whether a desired channel design can be microfabricated in a certain material to whether the material is compatible with the operating conditions (i.e., pressure, temperature) and the chemical composition (solvent, solutes) of the fluid used. Moreover, in certain cases, specific surface or bulk material properties can be used to the benefit of the application of the device. In the development of today's wide range of integrated micro- and nanofluidic applications, a common challenge emerges: meeting the often contradictory set of constraints imposed on the physical and chemical properties of materials by the envisioned applications. This issue reviews these challenges and their solutions and provides an outlook on how the ingenious use of existing and new materials can spur the development of ever more sophisticated micro- and nanofluidic systems.
\end{abstract}

Keywords: biological, fluidics, nanoscale.

\section{Introduction}

Micro- and nanofluidic systems have been around as long as the earliest cellular forms of life on our planet. In many biological species, including humans, microvascular systems-networks of convective flows that permeate their volumes-provide mass transfer of chemicals to and from certain locations. Early examples of artificial micro- and nanofluidics include micro syringe needles, glass capillaries, and a wide variety of membranes with micro- or nanopores. Advances in microand nanoscale fabrication and patterning methods have opened routes to attain micro- and nanofluidic networks of more sophisticated design and interconnectivity only over the last two decades. Three main categories of applications have inspired these rapid developments:

1. Microanalysis systems for purification, separation, and/or identification purposes; this was the original theme of microfluidics launched by Manz, Harrison, and Ramsey in the early $1990 \mathrm{~s}^{1}$ and has led to a variety of clinical and diagnostic tests, chemical and biological agent detectors, and environmental tests.

2. Microreactors for chemical synthesis; this younger field, which started in the late 1990s, has brought us, for example, methods to synthesize dangerous/unstable/ precious compounds on demand, ${ }^{2,3}$ fuel processing systems, ${ }^{4}$ synthesis of tailored nanoparticles, ${ }^{5}$ and microfuel cells. ${ }^{6}$

3. A wide range of enabling microfluidic tools for biological, biotechnological, and biomedical applications; these tools have burst on the scene over the past decade for purposes ranging from interacting with single cells ${ }^{7}$ to screening for appropriate crystallization conditions for proteins. $^{8}$

\section{Characteristics of the Microscale}

Before venturing into the materials aspects of the design, fabrication, and use of different micro- and nanofluidic chips, let's first consider the inherent implica- tions of performing chemical and biological processes in networks comprising channels of sub-millimeter dimensions. First, fluid flow is laminar (i.e., no turbulent mixing), as flows in micro- or nanofluidic channels are dominated by viscous dynamics, due to their higher surface-tovolume ratio, and are characterized by a Reynolds number $(\operatorname{Re}=V h / v<100$, where $V$ is the average velocity of the flow in meters per second, $h$ is the characteristic cross-sectional dimension of the channel in meters, and $v$ is the kinematic viscosity of the fluid in square meters per second). Due to the lack of turbulence, mixing of fluids is controlled by diffusion only. In laminar flows, the pressure required to push fluids through a channel scales with $1 / \mathrm{h}^{2}$ for a fixed velocity; depending on the flow speed and size of the network, this relationship may lead to pressure requirements that are experimentally inaccessible, for example, because of material failure.

Second, the smaller dimensions lead to higher rates of mass and heat transfer as a result of the steeper concentration and temperature gradients.

Third, compared with the macroscale, micro- and nanofluidic channels have very high surface-to-volume ratios. Having high surface-to-volume ratios enables, for example, the use of electro-osmotic flowflow driven by the interaction of an electric field with the net charge adjacent to a charged surface-rather than pressuredriven flow. On the other hand, higher surface-to-volume ratios may be detrimental for certain processes because of nonspecific adsorption, most notably in applications involving proteins.

In any micro- or nanofluidic application, some or all of these microscale characteristics have to be accounted for-or, ideally, exploited-in the design and function of devices.

\section{Microfabrication Methods}

The wide range of applications for micro- and nanofluidic networks and the characteristics of the microscale impose a wide variety of constraints on the materials used in their fabrication. Historically, the first micro- or nanofluidic systems were fabricated in silicon using the fabrication methods developed in the semiconductor industry for microelectromechanical systems (MEMS). ${ }^{9}$ The combination of photolithography and wet anisotropic etching allows complicated channel geometries to be created. Glass, Pyrex, and quartz have also long been substrates of choice, due to their chemical inertness and optical transparency. Glass offers an example of a fabrication constraint associ- 
ated with a material property: the isotropic character of glass etchants constrains the geometries that are accessible for channels formed in glass; high-aspectratio structures are difficult to form. On the other hand, researchers have taken advantage of the isotropic etching properties of glass to form channels with complex cross sections, for example, a controlled undercut of the masked areas. ${ }^{10}$ Ease of fabrication has led many researchers to pursue the use of polymeric materials, shaped into microfluidic networks using various molding strategies. The elastomer poly(dimethylsiloxane) (PDMS)-popularized by Whitesides, ${ }^{11}$ Beebe, ${ }^{12}$ and many others-is one of the more commonly used polymers in microfluidics. The desired channel designs can be obtained by replica molding from a master defined in standard photolithographic procedures. The resulting cross-linked material is highly transparent and seals well against itself and other surfaces, and the integration of pressure-fit interconnects is straightforward. Incompatibility with most organic solvents, however, has limited the use of PDMS to aqueous-based applications.

In addition to silicon, glass, and PDMS, many other materials, other fabrication methods, and combinations of materials are being used. One up-and-coming microfabrication technique is laser micromachining. With two or three different laser sources (e.g., a combination of a 197-nm Ti:Sapphire laser and a 1064-nm YAG laser), microfluidic channels can be machined in the surface of just about any material with a precision of $1 \mu \mathrm{m}$ or less. ${ }^{13}$ The key disadvantages of laser micromachining are its high equipment cost and the serial (and thus slow) nature of the process, whereas techniques based on photolithography, etching, or molding are parallel in nature.

\section{Choice of Materials}

Researchers often base their choice of materials on their familiarity with them and the associated methods of fabrication, or on the availability of appropriate fabrication facilities. With the field moving away from the fabrication and characterization of individual components toward a focus on the fabrication and application of integrated microchemical systems for specific chemical and biological purposes, decisions on what material or combination of materials to use must be based on the often stringent requirements of the envisioned application.

Material properties that have to be taken into account when making these decisions include:
- Compatibility with operating conditions (e.g., pressure, temperature), media, chemistries, and biological entities;

- Surface properties: roughness, zeta potential, wettability, bio-adhesion;

- Bulk properties: mechanical strength, transparency, thermal expansion, permeability; and

- Ease of integration with other materials: bonding/sealing possibilities.

In their article in this issue, Zhang and Haswell include a table that compares a range of these properties for the most frequently used materials for the fabrication of micro- and nanofluidic networks.

A DNA analysis device (Figure 1), as reported by Burns et al. in 1998, was one of the very first examples of a truly integrated microfluidic system. ${ }^{14}$ Burns's work exploited the wetting characteristics of his substrates-glass and silicon-to drive and regulate flow by capillarity. Another example of an integrated microchemical system in which material properties played a crucial role is Motorola's micro fuel processor for the conversion of methanol at $250^{\circ} \mathrm{C}$ into hydrogen for a fuel cell. ${ }^{4} \mathrm{~A}$ fuel processing chamber, a catalytic combustion chamber, a fuel vaporizer, resistive heaters, pressure and temperature sensors, and other components are integrated in layers of ceramic tape that are sintered together into a single fuel processing unit. Ceramics are known as excellent substrates to serve as catalytic supports. Key material challenges included matching thermal expansion coefficients and bonding dissimilar materials to deal with heating and cooling cycles.

From our own work (Kenis), we illustrate meeting combinations of material requirements for a microfluidic application through the synthesis of ceramic catalyst support structures for hydrocarbon reforming. ${ }^{15}$ To achieve high hydrocarbonto-hydrogen conversion per volume while avoiding coking of the catalyst (which takes place up to about $750^{\circ} \mathrm{C}$ ), we set ourselves the following requirements: (1) surface area of at least $5 \times 10^{5} \mathrm{~m}^{2} / \mathrm{m}^{3}$; (2) thermal stability above $800^{\circ} \mathrm{C}$; and (3) a high porosity to produce a low, experimentally readily achievable pressure drop across the structure. Whereas the high-

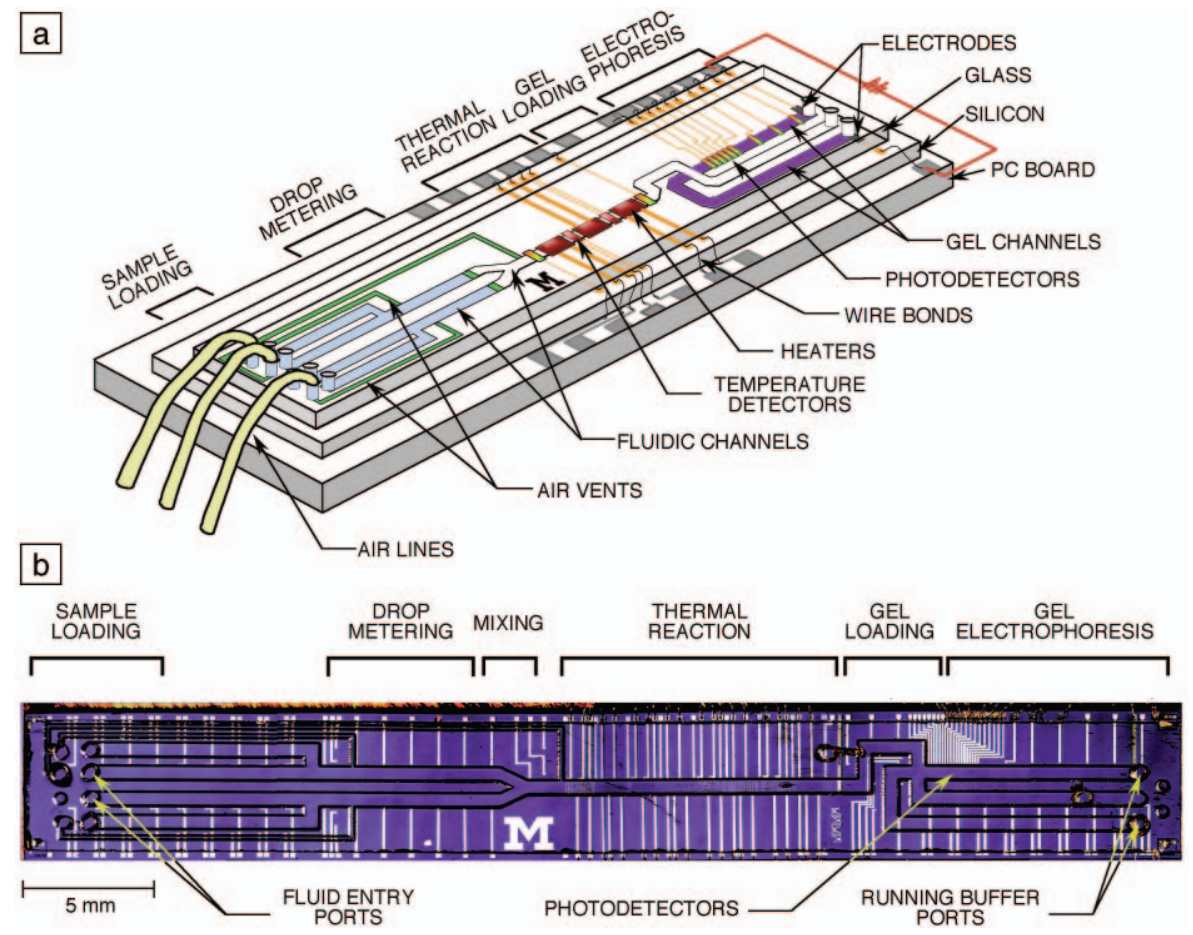

Figure 1. (a) Schematic illustration of an integrated microfluidic device with two liquid samples and electrophoresis gel present. The only electronic component not fabricated on the silicon substrate, except for control and data-processing electronics, is an excitation light source placed above the electrophoresis channel. Color code: blue, liquid sample (ready for metering); green, hydrophobic surfaces; purple, polyacrylamide gel. (b) Optical micrograph of the device from above. Wire bonds to the printed circuit board can be seen along the top edge of the device. The color arises from the interference filter reflecting the short-wavelength light. The pressure manifold and buffer wells that fit over the entry holes at each end of the device are not shown. ${ }^{14}$ 
surface-area features of oxides such as anodized alumina typically do not survive temperatures above $700^{\circ} \mathrm{C}$, the nonoxides, such as zeolites, typically do not meet the low-pressure-drop requirement. Figure 2 shows the highly porous, inverted beaded structure made out of $\mathrm{SiC}$ that we synthesized by infiltrating beds of packed polystyrene spheres with a preceramic polymer, followed by curing and sintering. ${ }^{15}$ Such $\mathrm{SiC}$ or SiCN catalyst support structures have surface areas as high as $7.4 \times 10^{7} \mathrm{~m}^{2} / \mathrm{m}^{3}$, are stable up to at least $1200^{\circ} \mathrm{C}$, and have a porosity of $\sim 0.7$, which ensures a low pressure drop. The integration of these catalyst structures into alumina reactor housings leads to integrated microfluidic reactors for hydrogen generation at $>99.8 \%$ conversion using ammonia as the fuel.

Many microfluidic designs are capable of performing only a few tasks at the same time. Performing many tasks in parallel, as desired in screening tools, was made possible by the advent of very large-scale integrated microfluidic networks (VLSImFNs) of PDMS (Figure 3) in which the elastomeric properties of PDMS are used to create arrays of integrated pneumatic valves that can also be used to create pumps and multiplexers all fabricated out of the same material. ${ }^{16,17}$ In each valve, two channels cross but are separated by a thin membrane of PDMS. If one of the channels is pressurized, the membrane bulges out into the second channel and closes it off (like stepping on a garden hose). Consecutive actuation of three pneumatic valves creates a peristaltic pumping mechanism. Such VLSI-mFNs have been used, for example, for DNA sequencing ${ }^{18}$ and protein crystallization. ${ }^{19}$ A startup company, Fluidigm, has already introduced VLSI-mFN-based microfluidic systems to the market that screen for suitable crystallization conditions. ${ }^{20}$

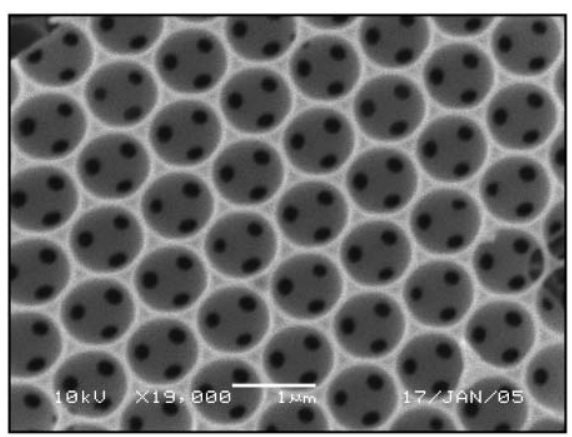

Figure 2. Scanning electron micrograph of a highly porous SiC catalyst support structure with thermal stability to over $800^{\circ} \mathrm{C}^{15}$

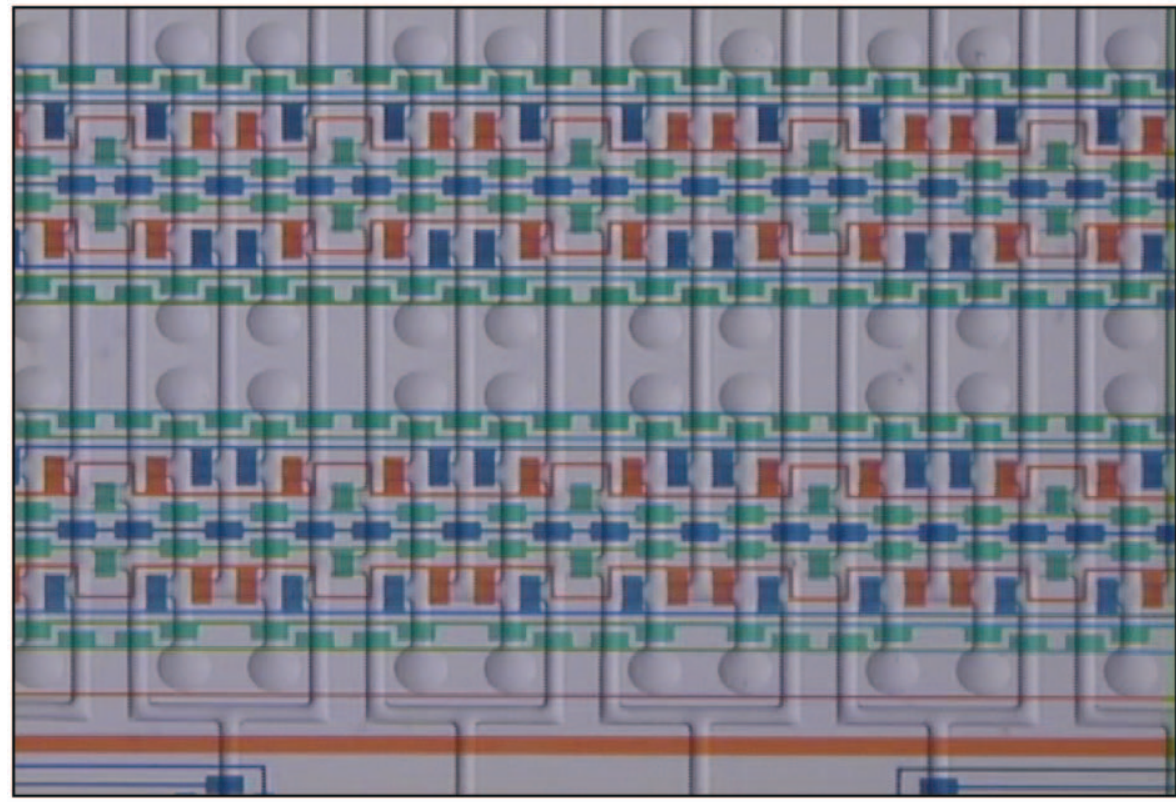

Figure 3. Optical micrograph of part of a very large-scale integrated microfluidic network (from S. Quake's research group, Stanford University): Three independently addressable networks (red, blue, green) of pneumatic valves (rectangles connected via very thin channels) enable pumping of fluid through the microfluidic channels (filled with clear solution) by consecutive actuation. ${ }^{16,17}$ The fluid channels are 50-100 $\mu \mathrm{m}$ wide. Photo by Sebastian Maerkl.

Micro- and nanofluidic systems have also been extensively integrated with electronics and photonics for detection and actuation purposes. In a recent report, a microfluidic device with integrated chemical sensing and electrowetting actuation on chemoreceptive neuron metal oxide semiconductor transistors was reported. ${ }^{21}$ Chemical sensing can also be accomplished through the integration of photonic crystal-based nanolasers. ${ }^{22}$

Several additional examples of integrated micro- and nanofluidic systems will be covered in the articles that follow this general introduction. In picking topics for these articles, we focused on covering a wide range of different materials, including silicon, glass, polymers, and hydrogels, as they are currently being used in micro- and nanofluidics. As the reader will see, the wide range of potential applications for microfluidic systems, ranging from analysis systems for pathogen detection to chemical synthesis and spectroscopic study tools, has been made possible by these developments. Each article discusses micro- and/or nanofluidic applications in light of various materials aspects, including the various compatibilities (conditions, chemistries), integration/bonding challenges, surface properties, and bulk properties briefly mentioned previously.
Zhang and Haswell provide a general review of how materials matter in the fabrication and operation of microfluidic systems. They look in more detail at the most popular materials and methods currently being used for chip fabrication. They also provide a treatment of how the high surface-area-to-volume ratios of microfluidic systems have been and can be exploited for various purposes.

After introducing the various advantages and disadvantages of metals, ceramics, glass, and polymers for various microfluidic applications, Jensen focuses on the use of silicon as the material of choice for a variety of applications: these range from chemical synthesis (screening of reaction conditions, synthesis of quantum dots) to heterogeneous catalysis (hydrocarbon fuel conversion, hydrogen purification). The challenges involved in the fabrication and operation of hybrid structures composed of more than one material are exemplified by the integration of various sensors (pressure, temperature, chemical composition) and meeting the requirements of optical transparency for spectroscopic applications (UV, IR).

Bakajin and Austin compare the benefits and drawbacks of elastomeric and nonelastomeric materials in the development of micro- and nanofluidic devices for DNA/RNA analysis and protein-folding 
studies. The authors provide a primer on the considerations of surface forces and solid mechanics in choosing materials for micro- and nanofluidic systems. Additionally, they emphasize the specific challenges that arise when precise submicrometer structures are required, and when applications using living cells are involved.

Stroock and Cabodi review initial efforts to implement microfluidic networks as synthetic vascular systems to control the chemical state inside materials used in biomedical applications. They highlight challenges that arise in microfabrication involving soft, organic biomaterials. Using tissue engineering and wound treatment as target applications, they illustrate basic design considerations that are relevant to the creation of these chemically active materials. Finally, they point toward the outstanding challenges in this emerging application of microfluidic technology.

Lastly, Simmons et al. discuss the fabrication and performance of microfluidic analysis systems in which species are separated using insulator-based dielectrophoresis (iDEP). These chips may find application in pathogen/bacterial analysis, sample preparation in microanalysis systems, and biomedical diagnostics. Their theoretical and experimental comparison of surface and bulk material properties shows how the choice of material (glass or polymer) can have a significant effect on throughput, detection efficiency, and cost of the microfluidic application.

\section{Current and Future Challenges}

The field of microchemical systems is increasingly focused on the creation of integrated systems for specific chemical or biological applications. Their development requires a balancing act to meet the often contradicting material requirements for the specific series of tasks. The lack of materials with specific combinations of properties also encourages innovation. For example, multiple new surface-modification approaches and bonding/sealing methods have emerged. Also, the incompatibility of PDMS with many organic solvents (which can cause swelling and dissolution) has spurred the development of perfluorocarbon-based elastomeric materials ${ }^{23}$ that are more compatible with typical organic solvents. Another emerging direction is the development of methods to fabricate arbitrary three-dimensional networks. Until recently, most approaches to obtain "3D" microfluidic networks involved sealing of layers, resulting in "2.5D" networks-essentially a series of connected 2D layers. Recently, the fabrication of 3D networks with arbitrary microfluidic interconnectivities using a direct-write approach has been reported. ${ }^{24}$ In addition, Ke et al. have recently reported another promising method to directly machine nanofluidic channels inside glass substrates through the use of a highly focused laser beam..$^{25}$

With researchers in academia and industry pursuing such a wide range of applications for microchemical systems, the rate of novel, ingenious materials solutions being reported will only increase. This issue of MRS Bulletin will review the wide range of materials aspects that need to be taken into account in the development of micro- and nanofluidic applications. Many examples are described, including several in which novel material solutions were crucial to their inception. We hope that these articles provide not just a good overview of the central role of materials in the development of microchemical systems, but also spur ideas for the ingenious use of new materials and methods of processing to allow for ever more integrated micro- and nanofluidic systems.

\section{References}

1. S.C. Jacobson, L.B. Koutny, R. Hergenröder, A.W. Moore Jr., and J.M. Ramsey, Anal. Chem. 66 (1994) p. 3472; D.J. Harrison, K. Fluri, K. Seiler, Z. Fan, C.S. Effenhauser, and A. Manz, Science 261 (1993) p. 895; A. Manz, D.J. Harrison, E.M.J. Verpoorte, J.C. Fettinger, H. Ludi, and H.M. Widmer, Chimia 45 (1991) p. 103.

2. S. Ajmera, M. Losey, and K.F. Jensen, AIChE J. 47 (2001) p. 1639.

3. R.C. Wootton, R. Fortt, and A.J. de Mello, Lab Chip 2 (2002) p. 5

4. D.L. Wilcox Sr., J.W. Burdon, R. Changrani, C.-F. Chou, S. Dai, R. Koripella, M. Oliver, D. Sadler, P. von Allmen, and F. Zenhausern, in Materials Science of Microelectromechanical Systems (MEMS) Devices IV, edited by A.A. Ayón, T.E. Buchheit, H. Kahn, and S.M. Spearing, (Mater. Res. Soc. Symp. Proc. 687, Warrendale, Pa., 2001) p. 225.

5. I. Shestopalov, J.D. Tice, and R.F. Ismagilov, Lab Chip 4 (2004) p. 316; A. Günther, M. Jhunjhunwala, M. Thalmann, M.A. Schmidt, and K.F. Jensen, Langmuir 21 (2005) p. 1547. 6. S.C. Kelley, G.A. Deluga, and W.H. Smyrl,
Electrochem. Solid-State Lett. 3 (2000) p. 407; J. Li, C. Moore, and P.A. Kohl, J. Power Sources 138 (2004) p. 211; E.R. Choban, L.J. Markoski, A. Wieckowski, P.J.A. Kenis, J. Power Sources 128 (2004) p. 54.

7. S. Takayama, E. Ostuni, P. LeDuc, K. Naruse, D.E. Ingber, and G.M. Whitesides, Nature 411 (2001) p. 1016

8. B. Zheng, L.S. Roach, and R.F Ismagilov, J. Am. Chem. Soc. 125 (37) (2003) p. 11170.

9. M. Madou, Fundamentals of Microfabrication (CRC Press, Boca Raton, FL, 1997).

10. A. Hibara, S. Iwayama, S. Matsuoka, M. Ueno, Y. Kikutani, M. Tokeshi, and T. Kitamori, Anal. Chem. 77 (3) (2005) p. 943.

11. D.C. Duffy, J.C. McDonald, O.J.A. Schueller, and G.M. Whitesides, Anal. Chem. 70 (1998) p. 4974.

12. B.H. Jo, L.M. Van Lerberghe, K.M. Motsegood, and D.J. Beebe, J. Microelectromech. Sys. 9 (1) (2000) p. 76.

13. See, for example, Potomac Laser Home Page, www.potomac-laser.com (accessed December 2005).

14. M.A. Burns, B.N. Johnson, S.N. Brahmasandra, K. Handique, J.R. Webster, M. Krishnan, T.S. Sammarco, F.P. Man, D. Jones, D. Heldsinger, V. Namasivayam, C.H. Mastrangelo, and D.T. Burke, Science 282 (1998) p. 484.

15. I.-K. Sung, N. Christian, M. Mitchell, D.-P. Kim, and P.J.A. Kenis, Adv. Funct. Mater. 15 (2005) p. 1336.

16. M.A. Unger, H.-P. Chou, T. Thorsen, A. Scherer, and S.R. Quake, Science 287 (2000) p. 113.

17. T. Thorsen, S.J. Maerkl, and S.R. Quake, Science 298 (2002) p. 580.

18. E.P. Kartalov and S.R. Quake, Nucleic Acids Res. 32 (9) (2004) p. 2873.

19. C.L. Hansen, E. Skordalakes, J.M. Berger, and S.R. Quake, Proc. Natl. Acad. Sci. USA 99 (26) (2002) p. 16531.

20. Fluidic Corp., Integrated Fluidic Circuits (IFCs) for the Life Sciences-Large Scale Home Page, www.fluidigm.com (accessed December 2005).

21. N.Y. Shen, Z.T. Liu, B.C. Jacquot, B.A. Minch, and E.C. Kan, Sens. Actuators B 102 (1) (2004) p. 35.

22. M.L. Adams, M. Loncar, A. Scherer, and Y.M. Qiu, IEEE J. Selected Areas in Commun. 23 (7) (2005) p. 1348.

23. J.P. Rolland, R.M. Van Dam, D.A. Schorzman, S.R. Quake, and J.M. DeSimone, J. Am. Chem. Soc. 126 (8) (2004) p. 2322; Liquidia Technologies Home Page, www.liquidia.com (accessed December 2005).

24. D. Therriault, S. White, and J.A. Lewis, Nature Mater. 2 (2003) p. 265; D. Therriault, R.F. Shepherd, S.R. White, and J.A. Lewis, Adv. Mater. 17 (4) (2005) p. 395

25. K. Ke, E.F. Hasselbrink, and A.J. Hunt, Anal. Chem. 77 (2005) p. 5083.

\section{Missing Important Issues of MRS Bulletin?}


Paul J.A. Kenis, Guest Editor for this issue of MRS Bulletin, is an assistant professor in the Department of Chemical and Biomolecular Engineering at the University of Illinois at Urbana-Champaign. He has affiliate appointments in the Department of Mechanical and Industrial Engineering, the Beckman Institute, the Institute for Genomic Biology, and the Micro and Nano Technology Laboratory. He is also an associate director of an NSF Nanoscience and Engineering Center for micro- and nanofluidicbased nanomanufacturing. Kenis received his BS degree in chemistry in 1993 from Nijmegen University in the Netherlands and his $\mathrm{PhD}$ degree in chemical engineering in 1997 from Twente University, also in the Netherlands. He was a postdoctoral fellow at Harvard University, where he worked on microanalysis systems and the development of novel microfluidic-based microfabrication techniques. In 2000, he joined the faculty at UIUC, where he pursues research in the area of microchemical systems. His present projects include the development of membraneless fuel cells, microreactors for hightemperature fuel reforming, microreactors for biocatalysis, platforms for biological cell studies, and micro/ nanofluidic tools for nanomanufacturing.

Kenis can be reached at the University of Illinois at UrbanaChampaign, Chemical and Biomolecular Engineering, 600 S. Mathews Avenue, Urbana, IL 61801, USA; tel. 217-2650523, fax 217-333-5052,

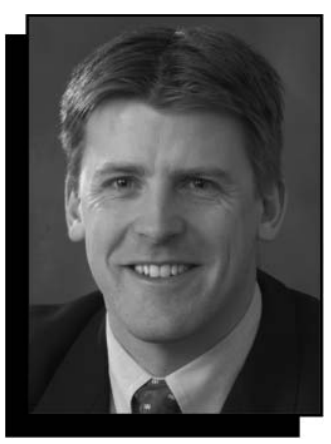

Paul J.A. Kenis

and e-mail

kenis@uiuc.edu.

Abraham D. Stroock, Guest Editor for this issue of MRS Bulletin, is an assistant professor in the School of Chemical and Biomolecular Engineering at Cornell University. He came to Cornell in 2003 from Harvard University, where he completed his PhD degree and a brief postdoctoral appointment with George M. Whitesides in the Department of Chemistry and Chemical Biology. His research focuses on coupling microfabrication and physicochemical principles of transport phenomena and soft materials. He aims to elucidate interesting behavior and address fundamental challenges in chemical and biomedical engineering. He is also a member of the graduate field of biomedical engineering.

Stroock can be reached at Cornell University, Chemical and Biomolecular Engineering, 360 Olin Hall, Ithaca, NY 14853, USA; tel. 607-255-4276, fax 607-255-9166, and e-mail rads10@cornell.edu.

Robert H. Austin is a professor of physics at Princeton University. He received his BA degree in 1986 from Hope College and his MS and

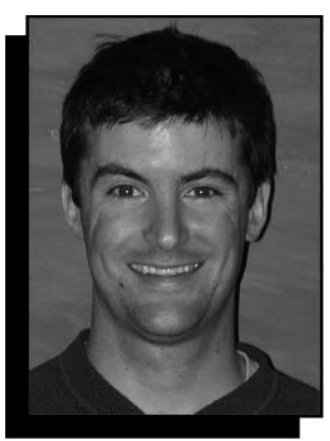

Abraham D. Stroock

PhD degrees in physics from the University of Illinois in 1970 and 1975, respectively. He did postdoctoral work in the Physics Department at the University of Illinois and at the Max Planck Institute for Biophysical Chemistry in Göttingen, Germany. He joined

Princeton in 1979 as an assistant professor, working his way up to his current position to which he was appointed in 1989. His research interests include protein dynamics, energy transport in biomolecules, DNA-protein interactions and topology, applications of microlithography to biology, and cell signaling.

Over the years, Austin has played an active role in the American Physical Society and was awarded the 2005 Lilienfeld Prize. Other honors include being a biophysics divisional editor for Physical Review Letters, a fellow of the American Association for the Advancement of Science, a member of the National Academy of Sciences, and chair-elect for the U.S. Liaison Committee for the International Union of Pure and Applied Physics.

Austin can be reached at Princeton University, Department of Physics, Princeton, NJ 08544, USA; tel. 609-258-4353

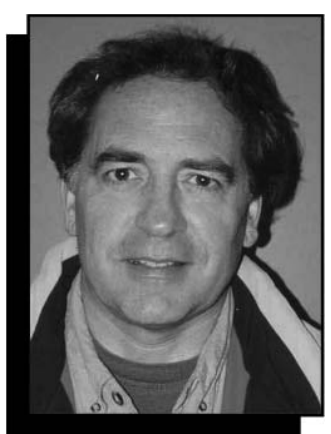

Robert H. Austin

and e-mail austin@ princeton.edu.

Olgica Bakajin is a staff physicist at Lawrence Livermore National Laboratory, where she leads a research group. She received her $\mathrm{AB}$ degree in physics from the University of Chicago in 1996 and her PhD degree in physics from Princeton University in 2000. She then joined LLNL as a Lawrence Fellow, spending the first nine months of her fellowship visiting the National Institutes of Health, working on microfluidic mixers for studies of protein folding. Her current interests include nanofluidics and applications of micro- and nanotechnology in the development of new tools for the study of biological systems.

Bakajin can be reached at Lawrence Livermore National Laboratory, Department of Chemistry and Materials Science, Livermore, CA 94550, USA; tel. 925422-0931, fax 925-4230579, and e-mail bakajin1@llnl.gov.

Mario Cabodi received his doctorate in physics from Cornell University in 2003, for work on entropic recoil separation of DNA in nanochannels with Harold Craighead. He then joined the

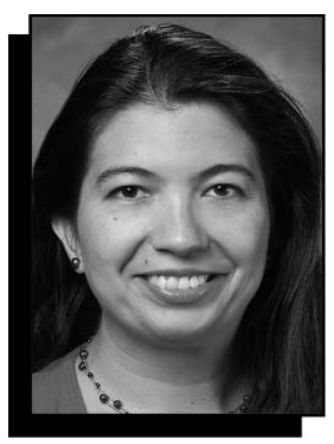

Olgica Bakajin

Stroock research group in chemical engineering, also at Cornell, where he has been involved in the development of microfluidics for biomedical engineering applications. His current research interests include microfluidiccontrolled scaffolds for cartilage tissue engineering and microfluidic wound dressings.

Cabodi can be reached at Cornell University, Chemical Engineering, 247 Olin Hall, Ithaca, NY 14853, USA; tel. 607-255-0501 and e-mail mc131@cornell. edu.

Stephen Y. Chou is the Joseph C. Elgin Professor of Engineering and the head of the NanoStructure Laboratory at Princeton University. He received his $\mathrm{PhD}$ degree from the Massachusetts Institute of Technology in 1986 and was a research associate and assistant professor at Stanford University until 1989. Between 1989 and 1997, he moved up from assistant professor to associate and then to full professor at the University of Michigan before joining Princeton in 1998. Also an entrepreneur, Chou founded Nanonex Corp. in 1999 and NanoOpto Corp. in 2000.

Chou is known for his work in a broad spec- 
trum of nanotechnologies and nanodevices, including ultra-small MOSFETs, quantum devices, single-electron transistors and memories, sub-wavelength optical elements, quantized magnetic disks, nanobio devices, nanoimprint lithography, laser-assisted direct imprint, and lithographically induced

self-assembly.

He has received numerous awards, including the 2004 IEEE Brunetti Award, IEEE Fellow, Packard Fellow, the Pioneer Award of Nanoimprint and Nanoprint Technology, the McKnight Land Grant Professorship, the George Taylor Distinguished Research Award at the University of Minnesota, and the DARPA ULTRA program Significant Technical Achievement Award. $\mathrm{He}$ is an inductee in the New Jersey High Technology Hall of Fame and holds three best paper awards. He has published more than 280 papers and given over 100 invited presentations at conferences and workshops, and holds 15 patents and over 40 patent applications.

Chou can be reached at Princeton University, Department of Electrical Engineering, B412 Engineering Quadrangle, Princeton, NJ 08544, USA; tel. 609-258-4416 and e-mail chou@ princeton.edu.

\section{Eric B. Cummings} started the Applied Microfluidic Physics Laboratory at Sandia National Laboratory in 1997. He received his $\mathrm{PhD}$ degree in aeronautics and chemistry from the California Institute of Technology in 1995 . He founded the companies

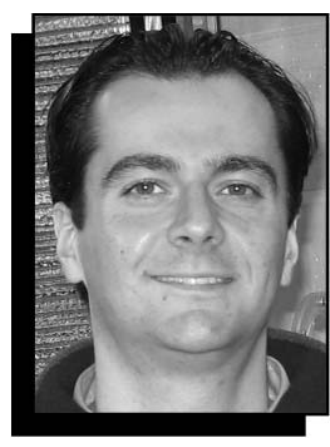

Mario Cabodi

LabSmith and CoolEarth Solar, and he has focused his research at Sandia on electrokinesis, dielectrophoresis, and rational microdevice design.

Cummings can be reached at LabSmith, 1159 Rebecca Dr., Livermore, CA 94550, USA; tel. 925-292-5161 and email ecummings@ labsmith.com.

\section{Rafael V. Davalos is a} senior member of technical staff in the Microfluidics Department at Sandia National Laboratories. He received his BS degree in mechanical engineering from Cornell University and his $\mathrm{PhD}$ degree in bioengineering from the University of California, Berkeley, in 2002. At Sandia, he has worked in the areas of molecular medicine, in vivo and in vitro electrical manipulation of cells, and microsystems development and engineering.

Davalos can be reached at Sandia National Laboratories, Microfluidics Group and Nanoscale Science and Technology Group, PO Box 969, Mail Stop 9154, Livermore, CA 94551, USA; tel. 925-29435049, fax 925-294-3866, and e-mail rvdaval@ sandia.gov.

Gregory J. Fiechtner is a principal member of

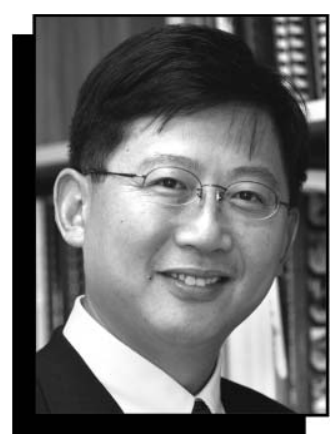

Stephen Y. Chou

technical staff in the Microfluidics Department at Sandia National Laboratories. He received his BS degree in mechanical engineering from the University of Nebraska in 1986 and his $\mathrm{PhD}$ degree in mechanical engineering from Purdue University in 1992. In addition to his seven years at Sandia, Fiechtner worked at the Air Force Research Laboratories in Dayton, Ohio, was a visiting faculty member at the University of Colorado and a visiting scientist at the Colorado School of Mines, and served a rotation in the Separations and Analysis Program with the U.S. Department of Energy in the Office of Basic Energy Sciences.

Fiechtner can be reached at Sandia National Laboratories, Microfluidics Group and Nanoscale Science and Technology Group, PO Box 969, Mail Stop 9292, Livermore, CA 94551, USA: tel. 925-2945809, fax 925-294-3020, and e-mail gjfiech@ sandia.gov.

Yolanda Fintschenko has been co-managing the Microfluidics

Department at Sandia National Laboratories since March 2004. She received her BS degree in chemistry from Trinity University in

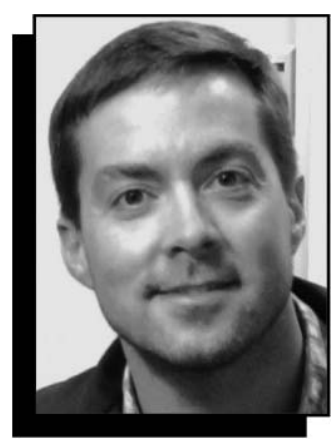

Eric B. Cummings

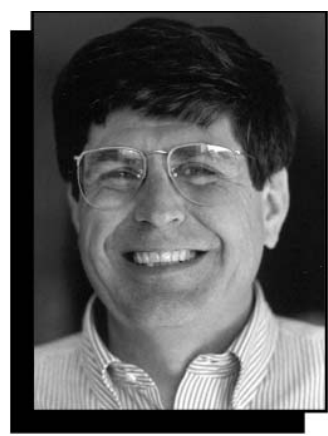

Klavs F. Jensen

1992 and her PhD degree in bioanalytical chemistry from the University of Kansas in 1997. She has been active in the field of microfluidics for approximately seven years, first as a postdoc at the University of Twente, then at Sandia National Laboratories, where she has worked on on-chip electrochromatographic separations using porous polymer monoliths and insulator-based dielectrophoresis for selective pathogen concentration.

Fintschenko can be reached at Sandia National Laboratories, Microfluidics Group and Nanoscale Science and Technology Group, PO Box 969, Mail Stop 9292, Livermore, CA 94551, USA; tel. 925-2944920, fax 925-294-3020, and e-mailyfintsc@ sandia.gov.

Eric Fountain is a graduate student in the

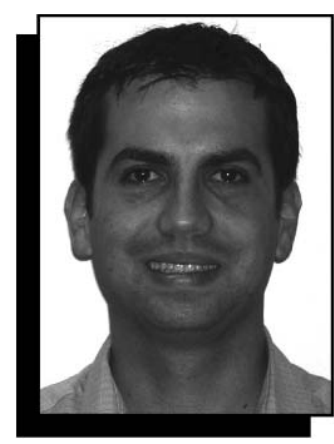

Rafael V. Davalos

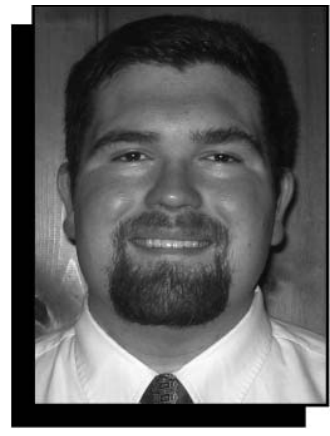

Gregory J. McGraw

Department of Physics at Princeton University. As an undergraduate at Duke University, he majored in physics and mathematics while conducting research in neuroscience and mathematical biology. With an inclination to pursue research with possible biomedical application, Fountain spent the 2004-2005 academic year working as a research technician for Robert H. Austin at Princeton. This work primarily focused on the fabrication and development of electrophoretic microarrays designed to quickly and effectively separate DNA.

Fountain can be reached at Princeton University, Department of Physics, 206 Jadwin Hall, Princeton, NJ 08544, USA; e-mail efountai@princeton.edu.

Steven J. Haswell is a professor of analytical 


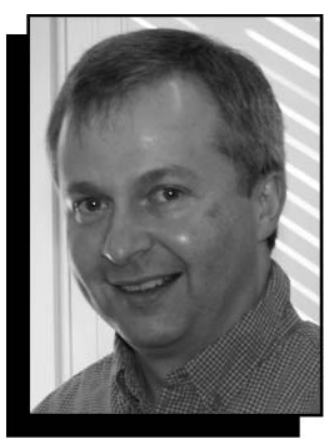

Gregory J. Fiechtner

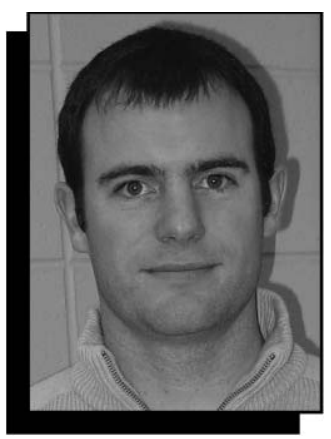

Keith Morton

chemistry at the University of Hull in England. He has research interests related to the fundamental and practical aspects of microreactor technology. Haswell is actively involved in many collaborative projects, involving more than 20 academic institutions and 30 industrial organizations drawn from eight overseas countries. His achievements include establishing the Foresight-funded Lab-on-a-Chip and Insight Consortium, being a founding member of the Centre for Process Analytics and Control Technology (CPACT), and coordinating EU programs in microwave chemical processing and chemometrics.

In 2000, Haswell was awarded the RSC Medal in Analytical Reactions and Analytical

Reagents, sponsored by Merck. He has approximately 150 publications, including a number of

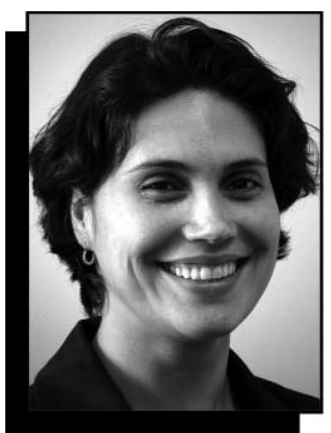

Yolanda Fintschenko

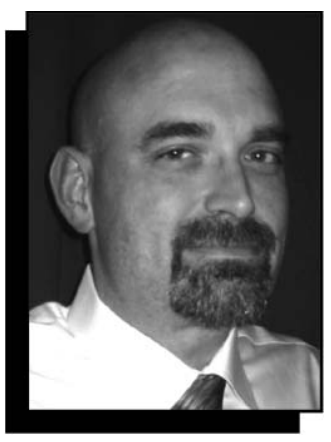

Blake A. Simmons

leading papers, patents, and reviews.

Haswell can be reached at the University of Hull, Department of Chemistry, Analytical Science Group, Hull HU6 7RX, United Kingdom; tel. 44-0-1482465469, fax 44-0-01482466416, and e-mail s.j.haswell@hull.ac.uk.

Klavs F. Jensen is the Lammot du Pont Professor of Chemical Engineering and a professor of materials science and engineering at the Massachusetts Institute of Technology. He received his MSc degree in chemical engineering education from the Technical University of Denmark and his PhD degree from University of Wisconsin-Madison. Prior to 1989 , he was a faculty member in the Department of Chemical Engineering and Materials Science at the University of Minnesota. His research interests re-

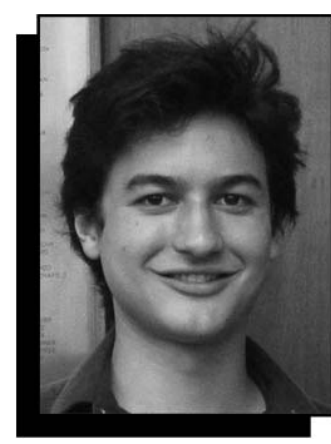

Eric Fountain

volve around microfabrication, testing, and integration of microsystems for chemical and biological discovery, synthesis, and processing. Chemical kinetics and transport phenomena related to processing of materials for biomedical, electronic, and optical applications are also topics of interest, along with the development of simulation approaches for reactive chemical and biological systems, specifically, simulation across multiple length and time scales.

Jensen is the recipient of an NSF Presidential Young Investigator Award; a Camille and Henry Dreyfus Foundation Teacher-Scholar Grant; a Guggenheim Fellowship; and the Allan P. Colburn, Charles C.M. Stine, and R.H. Wilhelm Awards of the American Institute of Chemical Engineers. He is also a member of the U.S. National Academy of Engineering and a fellow of the Royal Society of Chemistry.

Jensen can be reached at the Massachusetts Institute of Technology, Department of Chemical Engineering, Room 66566, 77 Massachusetts Avenue, Cambridge, MA 02139, USA; tel. 617-253-4589, fax 617258-8224, and e-mail kfjensen@mit.edu.

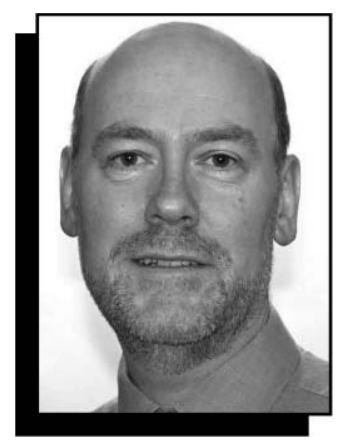

Steven J. Haswell

Gregory J. McGraw is pursuing a PhD degree in applied physics at the University of Michigan.

He received a BA degree in mathematics from Grinnell College in 2002 and an ME degree in chemical engineering from Cornell University in 2005 . He recently completed an internship in the Nanoscale Science and Technology Department at Sandia National Laboratories, where he was primarily responsible for the performance characterization of polymeric microfluidic devices.

McGraw can be reached at the University of Michigan, Rackam Graduate School, Applied Physics, 2477 Randall Laboratory, 500 E. University, Ann Arbor, MI 48109, USA; e-mail gmcgraw@ umich.edu.

Keith Morton is a doctoral candidate in electrical engineering at Princeton University. $\mathrm{He}$ received his $\mathrm{BSc}$ and MSc degrees in engineering physics in 1998 and 1999, respectively, from Queen's University in Canada. He then joined the Pressure Pipe Inspection Co. in Toronto as operations supervisor. In 2002, he joined the Nanostructures Laboratory at Princeton. His research interests include nano- fabrication, nanoimprint lithography, and nanofluidics for applications in biology.

Morton can be reached at Princeton University, Department of Electrical Engineering, C101 Equad, Princeton, NJ 08544, USA; tel. 609-258-6870 and e-mail kmorton@princeton.edu.

Blake A. Simmons is a principal member of technical staff in the Nanoscale Science and Technology Department at Sandia National Laboratories, where he works on the design, fabrication, integration, and testing of polymeric microfluidic devices for several lab-on-a-chip applications. He received his BS degree in chemical engineering from the University of Washington in 1997 and his PhD degree in chemical engineering from Tulane University in 2001.

Simmons can be reached at Sandia National Laboratories, Microfluidics Group and Nanoscale Science and Technology Group, PO Box 969, Mail Stop 9292, Livermore, CA 94551, USA; tel. 925-2942288, fax 925-294-3020, and e-mail basimmo@ sandia.gov.

James C. Sturm is a professor of electrical engineering and director of the Princeton Institute for the Science and Technology of Materials (PRISM) at Princeton University. He earned a BSE degree in electrical engineering and engineering physics from Princeton in 1979, followed by MSEE and $\mathrm{PhD}$ degrees from Stanford University in 1981 and 1985, respectively. He moved to Intel Corp. in 1979, where he was a microprocessor design 


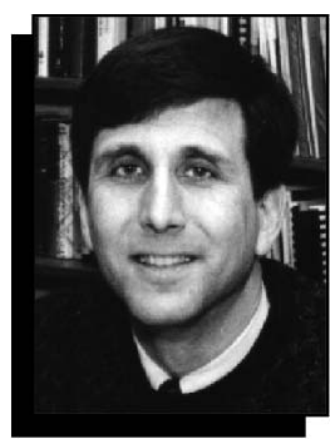

James C. Sturm

engineer until 1981

when he was a visiting engineer at Siemens Co. in Munich. He joined the faculty at Princeton in 1986, where he was also the director of the Center for Photonics and Optoelectronic

Materials (POEM) from 1997 to 2003.

Sturm's current research interests include

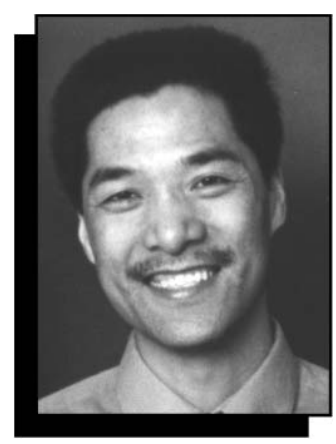

Xunli Zhang

silicon-germanium and related heterojunctions, large-area and organic electronics, and the nano-bio interface, although he has worked in the fields of siliconbased heterojunctions, three-dimensional integration, silicon-oninsulator, optical interconnects, TFTs, and organic light-emitting diodes. He is a co-founder of Aegis Semiconductor.

Sturm is the recipient of an NSF Presidential

Young Investigator

Award, many awards in teaching from Princeton, the W.M. Keck Foundation Award for Engineering Teaching Excellence, and an Alexander von Humboldt Fellowship. He is also an active participant in the materials research community, serving and chairing committees for organizations such as the Device Research Conference, IEDM, and MRS. $\mathrm{He}$ is a member of the American Physical Society and the Materials Research Society and an IEEE fellow.

Sturm can be reached at Princeton University,
Institute for the Science and Technology of Materials (PRISM) and Department of Electrical Engineering, 320 Bowen Hall, Prospect and Olden Streets, Princeton, NJ 08540, USA; tel. 609258-1575, fax 609-258-

1177, and e-mail sturm@ princeton.edu.

\section{Xunli Zhang is a re-} search scientist in the Department of Chemistry at the University of Hull in England. He received his PhD degree in chemistry from Imperial College London under the supervision of Mike Mingos.

Zhang specializes in microfluidic and lab-ona-chip technology and has $R \& D$ experience in both academic and in- dustrial environments. His extensive skills in programming dataacquisition and instrument-control software, together with his micro-fluidic modeling and microfabrication experience, have enabled his work in modeling, auto-mating, and integrating a number of microfluidic and detection systems with chemical and biological processing. He has published more than 20 papers and patents in the field since 2001.

Zhang can be reached at the University of Hull, Department of Chemistry, Analytical Science Group, Hull HU6 7RX, United Kingdom; e-mail x.zhang@hull.ac.uk.

\section{Trace Elemental Analysis, Worldwide}

World Leaders in Glow Discharge Mass Spectrometry

- Trace and Ultra Trace Elemental Analysis Laboratory

- Bulk, Near Surface and Depth Profile Elemental Evaluation

- Conductive, Non Conductive and Semi Conductive Materials Analysis from $\mathrm{H}$ to $\mathrm{U}$ (solids and powders)

- Minimum sample requirements (less than one gram required for 75 elements scan)

- Analytical Capabilities

- Trace Elemental Analysis by GD/MS

- Compositional Analysis by ICP-OES

- Metallography

- $\mathrm{C}$ and $\mathrm{S}$ by Combustion Technique

- N,O, H by Inert Gas Fusion

ISO 9002, NADCAP, GE-S400

Lab facilities in US, Europe and Asia

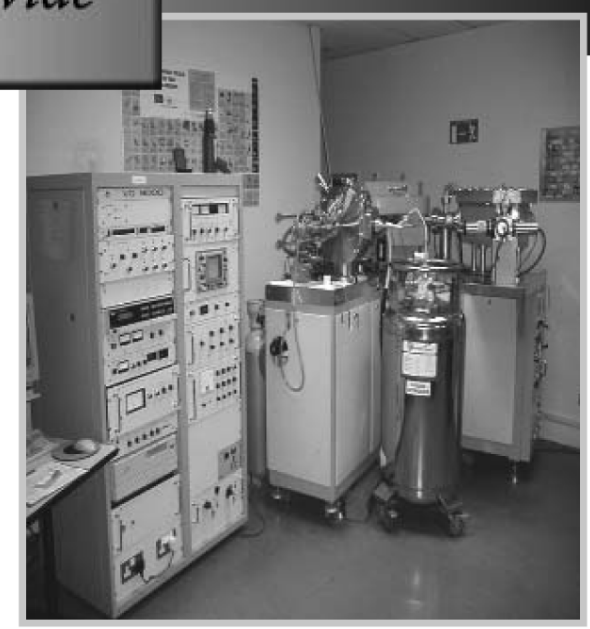

Shiva Technologies Inc.

6707 Brooklawn Parkway Syracuse, NY 13211

Phone: 315-431-9900

Fax: 315-431-9800 sales@shivatec.com 